Capítulo 11

\title{
Capitalismo de vigilância: a vertente Mattelart e a crítica aos processos midiáticos
}

DOI: https://doi.org/10.16921/ciespal.23.31

Andres Kalikoske

Universidade do Vale do Rio dos Sinos

(Processocom). São Leopoldo - RS, Brasil

\section{Resumo}

O artigo analisa o trinômio comunicação, capitalismo e sistemas de vigilância no âmbito dos processos midiáticos, recuperando as relações estabelecidas entre esses elementos desde as contribuições teórico-metodológicas de Armand Mattelart. A partir de uma perspectiva crítica, posiciona o papel articulador do teórico belga para a pesquisa em comunicação, considerando que as indústrias culturais contemporâneas já não se estabelecem a partir do simples diagrama que onde produção, circulação e consumo estabelecem convergências. Na contemporaneidade, as mídias digitais estão circunscritas em um tecido social complexo, no qual os intercâmbios de informação têm sido mediados por forças que atuam no cruzamento dos campos cultural, político, econômico e tecnológico. Nas duas últimas décadas, o interesse de interpretar os conglomerados transnacionais de tecnologia conduziu Mattelart a considerar como as programações algorítmicas têm sido exploradas com o intuito de extrair dados em escala de seus usuários. Nesse sentido, acreditando que a leitura de Mattelart, aqui revisitada, 
oferece possibilidades de reflexão sobre a condição dos processos midiáticos, o artigo apresenta subsídios para uma crítica do contrato social que é imposto pelas empresas de tecnologia que circundam o capitalismo de vigilância.

Palavras-chave: Mattelart. Capitalismo. Vigilância. Processos midiáticos.

\section{Introdução}

Com um percurso investigativo fundamentado no pensamento crítico e comprometido em denunciar os avanços do capitalismo global, o pesquisador belga Armand Mattelart tem sido uma referência também para pesquisadores interessados em compreender o atual momento da sociedade de consumo e seus mecanismos de vigilância. Historicamente, suas pesquisas estiveram voltadas às problemáticas dos meios de comunicação de massa, semeando uma sólida vertente para o estudo dos conglomerados de mídia e suas estratégias de transnacionalização. Mas a partir da publicação de La globalisation de la surveillance: aux origines de l'ordre sécuritaire, em 2007, Mattelart também tem se dedicado a interpretar os sistemas de informação, as tecnologias de vigilância e o poder de sedução de dispositivos portáteis extremamente leves e viciantes, capazes de influenciar relações sociais, as práticas de consumo e o ativismo em rede. Angulada pela lógica capitalista, a utilização de telas cada vez menores e interativas tem sido um balizador de uma nova forma de relação do ser humano com as mídias. Desde a perspectiva crítica da hipervigilância, a análise é que programações algorítmicas têm sido exploradas com o intuito de extrair dados em escala de seus usuários, servindo para ampliar o poder e a concentração de novos conglomerados transnacionais de tecnologia.

Desde a vertente Mattelart, compreender as lógicas dos conglomerados transnacionais de tecnologia - que nos últimos anos se infiltraram na comunicação - tem significado considerar seus cruzamentos 
culturais e movimentos histórico-sociais, as estruturas de poder que regem os grupos de mídia e questões geopolíticas de diferentes países, analisando com minúcia seus fluxos transnacionais e as implicações de seu consumo diante de um contexto de aperfeiçoamento tecnológico. Com esse propósito, o presente artigo busca recuperar as principais contribuições de Mattelart para o pensamento comunicacional crítico latino-americano, desde sua fase como crítico da comunicação imperialista e dos produtos da mídia de massa, entre as décadas de 1980 e 1990, passando por sua contribuição epistemológica, durante a década de 2000. A análise não linear explora, ainda, a abordagem denunciativa sobre o capitalismo de vigilância, que propondo alternativas para que a sociedade civil seja capaz de compreender, criticar e renegociar o contrato social imposto pelas empresas que circundam o capitalismo de vigilância.

\section{Crítica aos sistemas de informação e comunicação}

Mattelart está inserido no paradigma marxista dedicado a analisar as macroestruturas dos sistemas e fluxos de informação na América Latina e no mundo. Demógrafo por formação, sua militância política em greves estudantis o conduziu a escolher o Chile como morada latino-americana, logo passando a desenvolver pesquisas transversais às áreas da Comunicação durante o governo de Salvador Allende ${ }^{1}$. Por pouco não se estabeleceu no Brasil, aceitando um convite da Fundação Getúlio Vargas (FGV) do Rio de Janeiro. Mas a burocracia nacional estagnou sua vinda, refletindo o prognóstico gerado pelo golpe militar de 1964, que inviabilizou a presença de intelectuais progressistas alinhados com as lutas pelos movimentos sociais. Como pesquisador da Universidade Católica do Chile (UCC), Mattelart criou e coordenou o Centro de Estudos da Realidade Nacional (CEREN), realizando as primeiras

1 Maldonado, A. E. (2004). América Latina, berço de transformação comunicacional no mundo. In J. M. Melo \& M. C. Gobbi (orgs.). Pensamento comunicacional latino-americano: da pesquisa denúncia ao pragmatismo utópico (pp. 39-52). São Bernardo do Campo: UNESCO/UMESP. 
pesquisas sobre as multinacionais com atividades no país. Nesse momento, sua perspectiva sobre as macroestruturas das indústrias culturais pode ser lida em Multinacionais e Sistemas de Comunicação, estudo desenvolvido no Chile de Allende, e dedicado a analisar a penetração de empresas estrangeiras em países subalternos, modelo de negócio que "se estrutura à medida que as classes dominantes locais se convencem da eficácia dos esquemas e normas de produção já comprovados”2. Os caminhos estavam abertos para que Mattelart oferecesse contribuições significativas para desenvolver uma epistemologia crítica do campo da comunicação, o qual tem sido um dos principais pesquisadores e divulgadores, não somente no continente latino-americano mas também no mundo, por seu trânsito e influência científica.

Inicia sua trajetória considerando as mudanças processadas na sociedade europeia, inicialmente a partir da Revolução Industrial, e em seguida analisando suas problemáticas sociais diversas, que estabeleceram processos industriais capazes de formatar as bases de mercados midiáticos transnacionais - especialmente no que diz respeito à circulação da informação e à homogeneização da cultura. O contexto no qual Mattelart está inserido, nos anos 1960 e 1970, é marcado pela crise internacional do capitalismo, que a provocar declínios nas produções regionais, aumento de custos, baixos salários e aumento das desigualdades. Soma-se ao cenário o fortalecimento de grandes empresas, através da transnacionalização, o enfraquecimento dos governos como reguladores e a expansão das tecnologias de informação e comunicação ${ }^{3}$. Essa ambiência vem a instaurar, no âmago dos estudos comunicacionais centrados em desconstruir certezas, diversos debates sobre os modos de institucionalização da mídia eletrônica, os regimes comercial e público ${ }^{4}$. Nesse momento, as políticas públicas são cada vez mais combatidas por serem enquadradas como interferência estatal

2 Mattelart. A. (1976). Multinacionais e sistemas de comunicação: os aparelhos ideológicos do imperialismo. São Paulo: Ciências Humanas.

3 Mosco, V. (1996). The political economy of communication: rethinking and renewal. Londres: Sage.

4 Mattelart, A. \& Mattelart, M. (2001). História das teorias da comunicação (4a. ed.). São Paulo: Loyola. 
em negócios privados, o que, conforme os liberais (economicamente), retiraria a competitividade empresarial proporcionada pelo livre mercado, mas também porque, de acordo com outros liberais (politicamente), seria censura. Com esses dois pensamentos liberais cada vez mais próximos, a hegemonia acadêmica tende a subvalorizar o papel da regulamentação, ante o que seria a força da produção de sentido por parte dos receptores, bem como a super dimensão da mídia desvinculada dos grandes grupos econômicos. Mattelart resume bem a dificuldade de proposição e adoção de políticas públicas na atualidade:

A liberdade de comunicação não deve sofrer qualquer proibição. As reservas que podem ser feitas em relação a essa concepção da liberdade logo serão tachadas pelos grupos de pressão de tentativas de restauração da censura. Somente a sanção exercida pelo consumidor sobre o mercado de livre-oferta deve reger a circulação dos fluxos culturais e informacionais. O princípio de autorregulação tira a legitimidade de toda tentativa de formulação de políticas públicas, nacionais e regionais, no assunto. Não encontram acolhida nem sequer as interrogações sobre o papel que deve desempenhar o Estado em uma coordenação dos sistemas de informação e comunicação tendo em vista a preservação dos canais de expressão cidadã em relação às lógicas da segregação diante do mercado e da técnica, nem as que estão ligadas à função das organizações da sociedade civil como fator de pressão decisivo para exigir da autoridade pública essa arbitragem. $\mathrm{O}$ mundo se metamorfoseia em "comunidades de consumo" (consumption communities $)^{5}$.

Sob o viés político-organizacional, os estudos críticos em comunicação são impulsionados pelas propostas da Nova Ordem Mundial da Informação e Comunicação (Nomic), desenvolvidas nas reuniões da Organização das Nações Unidas para a Educação, a Ciência e a Cultura (Unesco). Ocorre, assim, um processo de desprendimento com as chamadas teorias da dependência cultural, desenvolvidas por Mattelart e demais pesquisadores. Naquele período, se abastecendo tanto

5 Mattelart, A. (2002). História da sociedade da informação. São Paulo: Loyola. 
da noção de hegemonia de Gramsci quanto das ideias sobre "aparelhos ideológicos" de Althusser, seu posicionamento passa a representar um contraponto aos produtos culturais estadunidenses e europeus, como quadrinhos, fotonovelas, cinema, televisão e música. Nesse movimento, dava-se ênfase ao estabelecimento de políticas nacionais de comunicação, acreditando que, com independência e autonomia, a mídia se democratizaria, buscando maior equilíbrio econômico e social. Em entrevista a Rebouças, Mattelart referencia o continente como a região pioneira na construção de um campo de estudo sobre a problemática da internacionalização na comunicação, alicerçadas em investigações inspiradas pelas teorias da dependência cultural. Contudo, na França foi preciso esperar até a segunda metade de 1980 para surgirem os primeiros estudos nesse sentido ${ }^{6}$. Conforme Mattelart e Neveu, entre os fatores responsáveis pelo distanciamento dos estudos culturais da política na América Latina, o principal seria a carência da problematização do novo estatuto do conhecimento no capitalismo, "caracterizado pelo duplo movimento de subsunção do trabalho intelectual e da intelectualização geral do trabalho"7. Isto se soma ao desconhecimento das análises da economia política das indústrias culturais e informacionais e à defasagem ante as mudanças do movimento social.

\section{Consumo, entretenimento e ideologia}

A partir de uma análise singular sobre os processos político-econômicos e suas interações com as mídias, Mattelartt ofereceu contribuições originais para a investigação das indústrias culturais. Não raramente o pesquisador é lembrado pelo best-seller Para ler o Pato Donald ${ }^{8}$,

6 Rebouças, E. \& Mattelart, A. (2002). Os riscos da perda da originalidade diante da generalização dos "estudos culturais": entrevista de Armand Mattelart. PCLA - Revista do Pensamento Comunicacional Latino-Americano, 4(1). Recuperado de: <http://www2.metodista.br//unesco/PCLA/revistal3/entrevista\%20 13-1.htm>. Acesso em: 27 jul. 2010.

7 Mattelart, A. \& Neveu, E. (2002). Introdução aos estudos culturais (pp. 155-156). São Paulo: Parábola.

8 Dorfman, A. \& Mattelart, A. (1978). Para ler o Pato Donald: comunicação de massa e colonialismo. Rio de Janeiro: Paz e Terra. 
cuja coautoria divide com o crítico literário Ariel Dorfman. Censurado nos Estados Unidos, o livro denuncia os produtos da Walt Disney como embaixadores da ideologia estadunidense, tornando-se um dos mais vendidos na América Latina, com 30 edições em língua espanhola e 15 em outros idiomas, contabilizando mais de um milhão de exemplares vendidos até $1996^{9}$. Não obstante, o pensamento de Mattelart, que no início dos anos 1970 estava centrado em denunciar as estratégias da propaganda imperialista praticadas por revistas de histórias em quadrinhos dos Estados Unidos, não deve ser visto como ruptura em relação à sua produção atual. Posteriormente, o pesquisador segue preocupado com as problemáticas que envolvem os bens simbólicos, nuances da cultura e tecnologia, a partir de uma crítica ao sistema regido por impérios hegemônicos.

O deslizamento que leva a comunicação a passar a uma definição com pretensões totalizantes, na visão de Mattelart ${ }^{10}$, substitui a "ideologia do progresso" pela "ideologia da comunicação", tarefa realizada por vulgarizadores técnicos e ideólogos-escritores, que fazem da "revolução tecnológica" um novo cavalo de batalha na luta contra tudo que mexe à sua esquerda; e colocam no campo dos simpatizantes do autoritarismo aqueles em desacordo com esse novo mito redentor. Na sociedade globalizada, as tecnologias de informação e comunicação e sua cultura são absorvidas como mercadorias, circulando como se superassem os conflitos do homem com ele próprio.

É nessa direção que deve ser pensado o papel da publicidade. Em 1982, a partir da coordenação da pesquisa Para um espaço audiovisual latino - resultante no livro Cultura contra democracia?, onde divide a autoria com Michèle e Xavier Delcourt -, Mattelart considera que, espalhada por tudo, as indústrias culturais - da TV ao turismo e à propaganda - buscam transformar a audiência em consumidores

9 Berger, C. (2001). A pesquisa em Comunicação na América Latina. In A. Hohlfeldt, L. C. Martino \& V. F. França (orgs.). Teorias da Comunicação: conceitos, escolas e tendências (pp. 241-277). Petrópolis: Vozes.

10 Mattelart, A. (1994). Comunicação-mundo: história das ideias e das estratégias (pp. 143-145). Petrópolis: Vozes. 
transnacionais, difundindo um conjunto de noções de desenvolvimento, comunicações, organização, vida diária e mudança, baseada no auto self-service ${ }^{11}$.

$O$ principal gênero da televisão brasileira também insere-se nessa categoria, sendo objeto dos Mattelart em $O$ carnaval das imagens ${ }^{12}$, através da identificação de como a necessidade de atingir mercados internos e externos tem conduzido os oligopólios de comunicação à realização de alianças sinérgicas, capazes de aumentar sua rentabilidade. A obra representa uma continuidade ao seu estudo anterior sobre transnacionalização, focalizando as dinâmicas do mercado brasileiro, uma das maiores indústrias audiovisuais do mundo, graças, em grande parte, ao gigantismo do mercado consumidor nacional. Este gigantismo refere-se especificamente à Globo, a primeira emissora a atribuir uma "importância capital"13 à medição de audiência, especialmente em seu prime time, como dizem os estadunidenses, ou a première soirée francesa, como também colocam os Mattelart em $O$ carnaval das imagens. As trocas transnacionais de bens culturais, não apenas no âmbito audiovisual, parte o entendimento de que:

Esta internacionalização é uma lógica tão impositiva que, por si só, autorizaria a parar aqui: no caráter globalizante do novo processo de produção dos bens materiais e simbólicos. Entretanto, nesta época de universalização das normas, nunca se sentiu tanto a necessidade de observar a maneira concreta e particular pela qual cada sociedade se articula na realidade envolvente do mercado e das trocas internacionais. ${ }^{14}$

O crescimento da Globo coincidiu com o interesse do governo militar em criar uma emissora que viesse a unir o território brasileiro, atendendo aos interesses das reformas econômicas e seu projeto político. A

\footnotetext{
11 Mattelart, A. (1983). Transnationals and the Third World: the struggle for culture. South Hadley, MA: Bergin and Garvey.

12 Mattelart, M. \& Mattelart, A. (1998). o Carnaval das Imagens. São Paulo: Brasiliense.

13 Mattelart, M. \& Mattelart, A. (1998). O Carnaval das Imagens (p. 58). São Paulo: Brasiliense.

14 Mattelart, M. \& Mattelart, A. (1998). o Carnaval das Imagens (p. 8). São Paulo: Brasiliense.
} 
estratégia inicial priorizou os programas populares para, sequencialmente, constituir um padrão tecnoestético qualificado, inviável de ser reproduzido por seus concorrentes naquele momento, onde a telenovela exercia - e ainda exerce - um papel preponderante. Identificam que, a partir da modernização da telenovela brasileira, no final dos anos de 1960, há uma aproximação da realidade. Antonio Maria (Tupi, 1968) e Beto Rockfeller (Tupi, 1968) foram as responsáveis pela ruptura do gênero melodramático. Seus personagens apresentavam qualidades e defeitos, com uma linguagem coloquial. Conforme Mattelart, é nesse momento que o público brasileiro se identifica na telenovela: os canais de TV "deixam de lado as lacrimejantes produções latinas para reconstituir o gênero com uma perspectiva e técnicas próprias. As falas tornam-se coloquiais; os diálogos soltos; desaparece o maniqueísmo; surge o herói sem qualidades, sujeito a erros e a acertos"15.

Ainda que a transnacionalização dos produtos nacionais siga uma tendência global - onde médias e pequenas corporações são absorvidas, sucumbem ou assumem posições inferiores mercadologicamente, dirigindo suas ações a públicos restritos, desejosos de estéticas alternativas -, os Mattelart colocam o problema central da dominação através do consumo popular, recorrente em suas análises, como no caso da penetração da telenovela: "a popularidade de uma telenovela não se mede somente pela" quantidade de audiência, mas pelo espaço que ocupam nas conversas cotidianas, "pelos boatos que alimentam, por seu poder de catalisar uma discussão nacional”, também acerca das questões sociais" ${ }^{16}$.

Este quadro globalizante garante ainda uma nova dimensão ao espaço local. Paralelamente à desterritorialização, que se expande sobre tudo, a desenraizar coisas, gentes, ideias e lugares, insere-se a reterritorialização, ou seja, o consumo elevado de bens globalizados conduz a uma valorização do local, do nacional. Conforme Armand e Michele Mattelart, o novo enfoque refere-se à desterritorialização

15 Mattelart, M. \& Mattelart, A. (1998). o Carnaval das Imagens (p. 31). São Paulo: Brasiliense.

16 Mattelart, M. \& Mattelart, A. (1998). o Carnaval das Imagens (p. 111). São Paulo: Brasiliense. 
simultaneamente à reterritorialização, de recomposição dos espaços particulares como unidades dotadas de sentido para as identidades ${ }^{17}$. A noção de reterritorialização envolve a valorização dos espaços e culturas locais, estabelecendo-se ainda vínculos próprios.

\section{Pensamento comunicacional revisitado}

Uma nova fase do capitalismo começa a se desenvolver nas últimas três décadas do século XX caracterizada pela articulação entre globalização e expansão do capital, neoliberalismo, privatização e desregulamentação de mercados, informatização e digitalização. Agregando robustez epistemológica de seus trabalhos anteriores, Mattelart passa a propagar sua hipótese de que a cultura deixou de ser um sistema uniforme e razoavelmente coerente, capaz de esclarecer as transformações do mundo, como propuseram os primeiros antropólogos. Sua compreensão sobre uma sociedade global e digital, assim como a observação de seus movimentos socioculturais, exigem análises cruzadas e sofisticadas, capazes de considerar as desigualdades de indivíduos inseridos em um mundo global e dominado pela técnica, no qual a própria cultura acaba por ser enquadrada como mercadoria cultural. Esse processo se difere, por exemplo, do momento em que a cultura estava em vias de industrialização ${ }^{18}$.

$\mathrm{Na}$ era da indústria cultural os conglomerados de comunicação se constituíram como produtores hegemônicos, maximizando suas presenças são somente através do lançamento de produtos midiáticos, mas também constituindo lobbies e articulações políticas para obtenção de vantagens diversas, não raramente com prejuízos aos direitos hu$\operatorname{manos}^{19}$. Na linha do enfoque denunciativo de Mattelart é possível

17 Mattelart, M. \& Mattelart, A. (1991). La recepción: el retorno al sujeto. Diálogos de la comunicación (p. 14), 30, 10-18.

18 Mattelart, A. (2002). História da sociedade da informação. São Paulo: Loyola.

19 Mattelart, A. (2009). A construção social do direito à Comunicação como parte integrante dos direitos humanos. Revista Brasileira de Ciências da Comunicação, 32, (1), 33-50. 
considerar, por exemplo, o avanço do setor privado e de instituições bancárias na manutenção da cultura - setor que, diante de dificuldades históricas de sustentabilidade, acaba por sucumbir aos recursos do capital financeiro transnacional. No âmbito político, a lógica capitalista tem evidenciado que os sujeitos sociais, os bens simbólicos e as significações resultantes dessas interações retroalimentam um sistema alienante, sendo a formação analítica de profissionais do setor comunicacional um dos maiores desafios do tempo presente. Progressivamente, os tentáculos do consumo passam a penetrar no cotidiano, instigando desejos, condicionando a vida social e promovendo a desigualdade.

Para além dos impactos nos âmbitos do desenvolvimento tecnológico e de inovação, essas empresas inserem-se no paradigma de reestruturação do capitalismo informacional. Com efeitos notórios a partir do final da década de 1990, uma nova estrutura social embalada pela reestruturação do capital financeiro começa a se constituir ${ }^{20}$. Em analogia ao colonialismo histórico de exploração petrolífera, o capitalismo contemporâneo se organiza na forma de colonialismo de dados, liderado por países como Estados Unidos e China, que buscam obter, processar e explorar dados digitais capazes de serem convertidos em uma nova forma de valor. Com a penetração das mídias digitais, a ciência de dados passa a sucumbir às lógicas do capital, detectando e prevendo padrões de comportamento e consumo que logo são convertidos em insights de negócios, geralmente distanciados de interesses sociais voltados a supressão de desigualdades. Paralelamente, esses movimentos de transformação e consumo estão inseridos em uma lógica macroestrutural, na qual o avanço neoliberal acaba remodelando a compreensão de cidadania da própria sociedade. Movimentos político-econômicos que envolvem os elevados índices de desemprego, o enfraquecimento dos sindicatos, a precarização do trabalho e o empreendedorismo forçado são alguns exemplos. Culturalmente, como resultado da deficiência histórica de reflexão social, cidadãos passam 
a operar como indivíduos-consumidores. "Não se trata mais de um consumidor qualquer, mas de um consumidor considerado soberano em suas escolhas, em um mercado também considerado livre"21.

Nesse sentido, uma análise bastante madura pode ser encontrada em História das Teorias da Comunicação ${ }^{22}$, livro que se dedica a sintetizar o desenvolvimento do pensamento crítico na Europa e na América Latina, ante o avanço das indústrias da mídia, no século XX. Os Estados Unidos, durante a década de 1960, teriam sido percussores do desenvolvimento da disciplina, com pesquisas que questionavam o desequilíbrio dos fluxos de informação e produtos culturais entre países ricos e em desenvolvimento. Os autores sintetizam que a perspectiva crítica retrata, desde sua origem, questões sobre o debate acerca dos dois modos de institucionalização da mídia eletrônica, o regime comercial e o serviço público, e citam uma das contribuições mais caras a disciplina a partir de 1975: o "abandono de uma visão demasiado genérica dos sistemas de comunicação"23, a partir da passagem da adoção do termo indústrias culturais, no plural. Os Mattelart analisam a mudança como uma ruptura com teóricos frankfurtianos, uma vez que estes partem do pressuposto de que todos os produtos culturais obedecem à mesma racionalidade técnica, organização e planejamento administrativo, semelhante ao da fabricação de automóveis ${ }^{24}$.

Para os economistas políticos da comunicação, por exemplo, o termo indústria cultural diz respeito aos processos de produção, circulação e consumo de bens culturais simbólicos, enquanto sua variante, no plural, parte do entendimento de que existem diversas indústrias, mercados e setores da produção cultural, cujos processos não ocorrem de maneira estanque. O desenvolvimento de uma teorização que contemple as indústrias culturais evidencia que os modelos clássicos são

21 Mattelart, A. (1999). História das teorias da comunicação (p. 152). São Paulo: Loyola.

22 Mattelart, A. \& Mattelart, M. (2001). História das teorias da comunicação (4a. ed.). São Paulo: Loyola.

23 Mattelart, A. \& Mattelart, M. (2001). História das teorias da comunicação (4a. ed.). (pp. 113-124). São Paulo: Loyola.

24 Mattelart, A. \& Mattelart, M. (2001). História das teorias da comunicação (4a. ed.). (pp. 122-123). São Paulo: Loyola. 
insuficientes, se não relacionados com abordagens mais atuais. Isto posto, os trabalhos sobre a indústria da cultura e da comunicação passaram a conquistar melhor norte, especialmente no que diz respeito à peculiaridade de cada uma das mídias e seus produtos. Entre os anos de 1980 e 1990, Mattelart inaugura uma perspectiva mais pluralista e conectada com as transformações socioculturais de seu tempo. Considerando a vertente histórica, começa a esmiuçar as lógicas do capitalismo e sua produção de desigualdades no tecido social.

\section{Fundamentos da hipervigilância}

Mattelart se insere na crítica ao capitalismo de vigilância alertando que, no momento posterior aos atentados de 11 de setembro de 2001, o governo estadunidense passa a investir em tecnologias de identificação social, aparelhando recintos públicos com dispositivos que logo se converteram em sistemas permanentes. Seu legado crítico em relação ao imperialismo estadunidense alcança novos voos, atualizando a problemática da digitalização cultural e da hipervigilância, implementada por governos dos Estados Unidos e da China. Passados mais de 4.0 anos após o lançamento de suas primeiras obras na América Latina, Mattelart revisita sua produção e relativizou visões condenatórias sumárias que caracterizavam sua produção inicial, ainda que sem abster-se do compromisso crítico que o caracterizou ${ }^{25}$. Seu livro sobre o nascimento de uma sociedade hiperconectada e digitalmente vigiada ${ }^{26}$ segue essa direção. $\mathrm{Na}$ obra, Mattelart preocupa-se com as políticas de comunicação dos meios e a questão informacional. Paralelamente aos movimentos teóricos do pesquisador, cabe ponderar que, nesse momento, as empresas de mídia estavam em vias de transformação: como em nenhuma outra época, estavam se tornando fundamentalmente empresas de tecnologia. A automação

25 Maldonado, A. E. (2015). Epistemología de la comunicación: análisis de la vertiente Mattelart en América Latina. Quito: CIESPAL.

26 Mattelart, A. (2007). La globalisation de la surveillance: aux origines de l'ordre sécuritaire. Paris: La Découverte. 
de sistemas passa a permitir uma maior exploração da participação (ou do protagonismo moldado pelo capital) de usuários nos processos produtivos, assim como a diminuição da demanda de trabalho de profissionais de comunicação e o aumento da requisição de profissionais que atuam na interface da inovação e da tecnologia.

No âmbito das Ciências Sociais, um olhar atento sobre os sistemas de vigilância surge nos anos 1980, nos primórdios do projeto de digitalização da informação, Schiller alerta sobre a complexidade da questão e a possível reordenação dos modos de vida - que vem a concretizar-se -, a partir da integração de setores consolidados, como o econômico, até os ainda emergentes como a nanotecnologia e a biotecnologia. Nesse tempo, Schiller considera que uma espécie de manipulação informacional poderia a ser delineada, uma vez que "os arquitetos do capitalismo digital tinham em vista um objetivo principal: criar uma rede econômica alargada que pudesse apoiar o leque cada vez mais amplo de projetos no interior das empresas e no relacionamento entre elas" 27 . O digital é oferecido ao consumidor, na segunda metade dos anos 1990, através de "computadores transmissores de sinais de áudio, vídeo, imagem e dados, requerendo a total alteração da regulamentação e das estruturas de telecomunicações dos diversos países" ${ }^{28}$. Essa sedutora proposta multimídia, gradualmente torna-se mediador da vida social, papel antes desempenhado pela televisão.

O discurso denunciativo de Schiller, que então ecoa alarmista entre os pesquisadores da Comunicação, encontra fôlego nas reflexões de Mattelart. Em História da Sociedade da Informação, o pesquisador descreve o surgimento da National Security Agency (NSA), idealizada pelos Estados Unidos e seus quatro países sócios (Canadá, Grã-Bretanha, Austrália e Nova Zelândia), interessados em "recolher o máximo de informações sobre a União Soviética e seus aliados" ${ }^{29}$. A NSA acaba constituindo-se em um potente sistema de inteligência, resguardando 
interesses econômicos e de segurança dos Estados Unidos. Ainda que tenha sido incapaz de prevenir os atentados ocorridos em 11 de setembro, especialmente pelas técnicas de camuflagem (estenografia) utilizadas por Osama Bin Laden e seus seguidores, a NSA conta com "sistemas planetários de escuta das comunicações" e satélites-espiões integrados, dotados de tecnologia de última geração para a captura de "imagens com uma precisão de 15 centímetros" ${ }^{30}$.

Na qualidade de pesquisador astucioso e atento, durante a década de 2000 Mattelart segue acompanhando exaustivamente o mundo em transformação e os avanços das mídias no tecido social, examinando a importância da comunicação contemporânea para a história recente do sistema capitalista. Acende importantes precedentes para compreendermos como os sistemas de vigilância podem reconfigurar tomadas de decisão e preferências de consumo, com fortes prejuízos para uma concepção cidadã da vida em sociedade. Nesse sentido, o pesquisador sinaliza que os sistemas de segurança estadunidense e as políticas de prevenção (alarmistas e com conotações terroristas) passam a amparar princípios do regime democrático vigente no país. O governo de George Bush, buscando elevar sua popularidade, passa a legitimar o desenvolvimento de tecnologias de vigilância, não tardiamente obtendo informações privilegiadas sobre os segmentos mais amplos da vida social. Inicia-se uma espécie de resposta aos sistemas de vigilância, a partir de uma série de vazamentos de informações diplomáticas.

De fato, os alertas de Schiller ou "o mundo vigiado" de Mattelart ultrapassam os limites da internet, atingido o cotidiano da sociedade civil. Os direitos de privacidade tornam-se gradualmente revogados: as organizações, quase que em sua totalidade, começam a utilizar sistemas biométricos, que no discurso estadunidense são sinônimos de sistemas infalsificáveis; câmeras portáteis já não estão presentes somente nos grandes estabelecimentos comerciais ou locais de amplo acesso, mas incorporadas ao planejamento urbano, em todas as residências, 
avenidas e ruas, parques e praças das maiores cidades do mundo; nos computadores, cookies de rastreamento passam a armazenar dados nos navegadores de internet, mapeando os padrões de consumo dos usuários; e até mesmo fotos digitais armazenadas na rede podem carregar consigo elementos geográficos, acusando onde foram fotografadas, uma vez que celulares e câmeras de última geração contam com a tecnologia Global Positioning System (GPS) incorporada ${ }^{31}$. Mais recentemente, caminha-se no sentido da câmera personalizada: cada indivíduo poderá carregar consigo uma câmera pouco perceptível, em formato de óculos, a partir da proposta de realidade aumentada do Google Glass.

\section{Capitalismo de vigilância}

Hoje sabemos que os resultados de uma pesquisa no Google não são os mesmos para todos: há seleção de conteúdos e cada usuário pode se deparar com um Google personalizado para si. Os processos midiáticos contemporâneos exploram lógicas diferentes dos meios de comunicação de massa do passado, que lançavam na arena social pautas generalistas e passíveis de discussão em toda a sociedade. Conforme Pariser, "a democracia exige que nos baseemos em fatos compartilhados; no entanto, estão nos oferecendo universos distintos e paralelos". ${ }^{32}$ Com o recebimento de diferentes níveis de informação, a transparência fica prejudicada, assim como a ideia de que a internet pode uma mídia capaz de proporcionar o exercício da cidadania sem algum letramento prévio. Não obstante, no âmbito do consumo, o problema maior do capitalismo de vigilância, conforme está sendo implementado pelo Google, pode ser seu cruzamento com a vida social. Por exemplo, com fácil acesso aos dados de seus usuários, os bancos podem ampliar ou limitar linhas de crédito conforme o padrão de consumo de seus correntistas; os planos

31 Wünsch, S. (2013, julho 13). Espionagem da NSA mostra como metadados podem expor segredos. Deutsche Welle. Recuperado de: 〈https://p.dw.com/p/1974t>. Acessado em: 30 jun. 2019.

32 Pariser, E. (2012). O filtro invisível: o que a internet está escondendo de você. São Paulo: Zahar, 
de saúde podem aumentar as franquias se forem balizados por hábitos e estilos de vida de seus clientes; ou ainda, uma companhia de seguros pode considerar os padrões de comportamento na hora de precificar seus produtos.

$\mathrm{Na}$ análise do mundo vigiado de Mattelart o produto é o indivíduo. Seguindo lógicas diferentes das tradicionais mídias de massa, os modernos conglomerados transnacionais de tecnologia passam a investir em uma oferta diversa de produtos digitais. Inauguram, assim, era da dataficação, posicionando empresas especializadas em um mix de gestão da informação, exploração de capital humano participativo, publicidade segmentada, distribuição de produtos ou serviços digitais como jogos e aplicativos, etc. Processos de extração e monetização de dados cooptados por softwares como Facebook, Apple, Amazon, Google e Wireless Lab viriam a laurear o alertas anteriores do pesquisador.

Mas esse processo começa a se desenvolver em escala global em 2004, quando surge a rede social Facebook, uma das mais completas categorizações de seres humanos do mundo. Nos últimos anos, seu rol de negócios tem incluído o repasse destas informações a terceiros, uma vez que o Facebook tem incorporado em sua plataforma diversos aplicativos desenvolvidos por empresas de tecnologia terceirizadas. Uma vez instalados (download), os aplicativos terceirizados requerem o password do Facebook, levando consigo uma infinidade de informações espontaneamente declaradas nesta mídia social. Nesses casos, as políticas de privacidade, ainda que oferecidas, são ambíguas e imprecisas, não raramente confundindo os usuários. Paralelamente, eleva-se a compreensão de que o uso satisfatório da internet, sob o ponto de vista da segurança e privacidade, consiste no desenvolvimento de uma conscientização coletiva, acerca da responsabilidade sobre as informações postadas e compartilhadas. Contudo, trata-se de uma dicotomia extremamente complexa, uma vez que ainda existe a falsa noção de anonimato. Circunscrevem-se ainda problemas como propriedade intelectual, controle ou censura, pornografia e violências, de modo geral, 
como bullying, difamação e racismo, sendo estes três últimos especialmente caros às redes sociais.

Os procedimentos de vigilância social adotados pelos Estados Unidos são reevidenciados a partir de 2006, com o surgimento da Wikileaks. Sediada na Suécia, a organização transnacional sem fins lucrativos passa a difundir, via internet, informações confidenciais diplomáticas fornecidas por fontes anônimas. $\mathrm{O}$ ano de 2013 torna-se emblemático, uma vez que Edward Snowden, um ex-analista da NSA, alerta o mundo, através dos jornais The Guardian e The Washington Post, sobre o programa de vigilância digital massiva desempenhado pela NSA. Em carta interessada aos brasileiros, Snowden refere-se a situações cotidianas para explicitar o alcance dos programas de vigilância em massa. Conforme o antigo analista, "se você carrega um celular em São Paulo, a NSA pode rastrear onde você se encontra, e o faz: ela faz isso 5 bilhões de vezes por dia com pessoas no mundo inteiro"; também, prossegue Snowden, "quando uma pessoa em Florianópolis visita um site na internet, a NSA mantém um registro de quando isso aconteceu e do que você fez naquele site"; ou ainda, "se uma mãe em Porto Alegre telefona a seu filho para lhe desejar sorte no vestibular, a NSA pode guardar o registro da ligação por cinco anos ou mais tempo"; por fim, assegura que, "a agência chega a guardar registros de quem tem um caso extraconjugal ou visita sites de pornografia, para o caso de precisarem sujar a reputação de seus alvos"33.

No contexto brasileiro os desafios são enormes. O modelo neoliberal avança em diversos setores da sociedade alardeando as potencialidades da tecnologia sem investimentos paralelos em recursos humanos. Sistemas de informação são abastecidos por um bancos de dados, isoladamente, sem preocupação com a promoção de cidadania. A carência de um letramento midiático prejudica a forma como os usuários consomem os conteúdos na internet comprometendo a autonomia e o pensamento crítico da sociedade em geral. A ampliação

33 Allain, C. (2013, dezembro 17). Leia íntegra da carta de Snowden ao Brasil. Folha de São Paulo. Recuperado de: <https://wwwl.folha.uol.com.br/mundo/2013/12/1386291-leia-integra-da-carta-de-snowden-ao-brasil.shtml>. Acesso em: 30 set. 2020. 
de as notícias falsas e o ambiente de pós-verdade, ampliado através da distribuição deliberada de desinformação, é um dos resultados desse processo. Outra questão central na cultura capitalista é que as tecnologias estão sendo empregadas para explorar ainda mais as forças de trabalho. ${ }^{34}$ Empresas de tecnologia, de modo geral, são sistemas conectados para produção, controle e circulação de mercadorias. Entre as transformações mais latentes podemos citar o nomadismo digital e as atividades remotas. Esse movimento, esquadrinhado nos últimos anos, fica evidente a partir da crise gerada pela pandemia de coronavírus (SARS-CoV-2), que acelerou o processo de desestruturação do modelo empresarial tradicional que perdurou durante o século XX. Para além da flexibilização das horas trabalhadas e das atividades multissetoriais desempenhadas pelo mesmo colaborador, há a utilização da infraestrutura tecnológica doméstica dos próprios empregados, muitas vezes sem contrapartida das empresas. Como sintoma, também há um maior distanciamento entre formação e atuação profissional. Essas questões se agravam a partir de 2019, momento em que o Brasil atravessa um processo de precarização em sua rede de proteção social, notadamente pela fragilização das instituições e redução drástica de orçamentos em setores estratégicos capazes de assegurar a dignidade humana. Contudo, não se trata de recusar os avanços tecnológicos, mas sobretudo, seguindo os passos de Mattelart, de questionar como a tecnologia tem sido consumida e aplicada nos diversos setores da sociedade.

\section{Considerações finais}

A vertente Mattelart segue se perpetuando e iluminando a pesquisa crítica em comunicação entre as novas gerações. Coerente e comprometida a denunciar a folia capitalista, Mattelart tem sido uma alternativa para investigações sobre contra-hegemonia, democratização da cultura, políticas e as tecnologias de comunicação, presença

34 Figaro, R (2018). Comunicação e trabalho: implicações teórico-metodológicas. Galáxia, 39, (3), p. 177-189. 
de interesses transnacionais nos mercados das indústrias culturais e, mais recentemente, os sistemas globais de vigilância. $\mathrm{O}$ eixo teórico-metodológico que o pesquisador belga desenvolveu e sua escolha pelas macroestruturas o transformaram em um autêntico analista dos sistemas transnacionais de comunicação. Diante do incremento econômico da chamada era digital e de sua constituição tecnológica, seus estudos mais recentes passaram a iluminar análises posteriores sobre as novas indústrias (digitais) e os modelos de comercialização em desalinho, as possibilidades e os impactos da internet ante a convergência de mídias, os novos esquemas de produção, distribuição e consumo de conteúdos, as mídias digitais e suas implicações no rol dos sistemas de vigilância.

Desde o viés anticolonizador presente em seus primeiros trabalhos até seus períodos de amadurecimento e consolidação, responsáveis pela constituição de uma epistemologia histórica e crítica do campo da comunicação, Mattelart foi um dos pioneiros em vislumbrar, na segunda metade dos anos 2000, como operavam os conglomerados transnacionais de tecnologia. A tríade penetração cultural, poder e capital não esclarece a complexidade e variedade dos negócios desses conglomerados, mas oferece pistas para analisarmos como, histórica e socialmente, souberam explorar com relativa competência os sistemas políticos, as oportunidades de mercado e o potencial econômico de seus produtos culturais para se perpetuar no poder durante os últimos 70 anos.

No limiar da década de 2020, Mattelart segue contribuindo para enfatizar, com todo rigor teórico-metodológico que caracteriza o pesquisador, as problemáticas econômicas e políticas que são instauradas ao redor dos sistemas transnacionais de comunicação. Da análise crítica das indústrias culturais ao tom denunciativo sobre a extração de dados, os prejuízos à privacidade e o cerceamento da liberdade no contexto capitalista, sua vertente segue se apresentando como uma alternativa qualificada para pesquisadores interessados em dissecar os conglomerados de tecnologia que se utilizam de sistemas de informação para penetrar seus tentáculos na vida social. 


\section{Referências}

Allain, C. (2013, dezembro 17). Leia íntegra da carta de Snowden ao Brasil. Folha de São Paulo. Recuperado de: <https://www1.folha.uol.com.br/mundo/2013/12/1386291-leia-integra-da-carta-de-snowden-ao-brasil.shtml>. Acesso em: 30 set. 2020.

Berger, C. (2001). A pesquisa em Comunicação na América Latina. In A. Hohlfeldt, L. C. Martino \& V. F. França (orgs.). Teorias da Comunicação: conceitos, escolas e tendências. Petrópolis: Vozes.

Dorfman, A. \& Mattelart, A. (1978). Para ler o Pato Donald: comunicação de massa e colonialismo. Rio de Janeiro: Paz e Terra.

Figaro, R (2018). Comunicação e trabalho: implicações teórico-metodológicas. Galáxia, 39, (3), p. 177-189.

Maldonado, A. E. (2004). América Latina, berço de transformação comunicacional no mundo. In J. M. Melo \& M. C. Gobbi (orgs.). Pensamento comunicacional latino-americano: da pesquisa denúncia ao pragmatismo utópico (pp. 39-52). São Bernardo do Campo: UNESCO/UMESP.

Maldonado, A. E. (2015). Epistemología de la comunicación: análisis de la vertiente Mattelart en América Latina. Quito: CIESPAL.

Marx, K. (1971). O capital: crítica da economia política (21a. ed.). Rio de Janeiro: Civilização Brasileira.

Mattelart, A. \& Mattelart, M. (2001). História das teorias da comunicação (4a. ed.). São Paulo: Loyola.

Mattelart, A. \& Neveu, E. (2002). Introdução aos estudos culturais. São Paulo: Parábola.

Mattelart, A. (1983). Transnationals and the Third World: the struggle for culture. South Hadley, MA: Bergin and Garvey.

Mattelart, A. (1994). Comunicação-mundo: história das ideias e das estratégias. Petrópolis: Vozes.

Mattelart, A. (2002). História da sociedade da informação. São Paulo: Loyola.

Mattelart, A. (2007). La globalisation de la surveillance: aux origines de l'ordre sécuritaire. Paris: La Découverte.

Mattelart, A. (2009). A construção social do direito à Comunicação como parte integrante dos direitos humanos. Revista Brasileira de Ciências da Comunicação, 32, (1), 33-50.

Mattelart, M. \& Mattelart, A. (1991). La recepción: el retorno al sujeto. Diálogos de la comunicación, 30, 10-18. 
Mattelart, M. \& Mattelart, A. (1998). O Carnaval das Imagens. São Paulo: Brasiliense.

Mattelart. A. (1976). Multinacionais e sistemas de comunicação: os aparelhos ideológicos do imperialismo. São Paulo: Ciências Humanas.

Mosco, V. (1996). The political economy of communication: rethinking and renewal. Londres: Sage.

Rebouças, E. \& Mattelart, A. (2002). Os riscos da perda da originalidade diante da generalização dos "estudos culturais": entrevista de Armand Mattelart. PCLA - Revista do Pensamento Comunicacional Latino-Americano, 4(1). Recuperado de: $<$ http://www2.metodista.br//unesco/PCLA/revista13/entrevista\%2013-1.htm>. Acesso em: 27 jul. 2010.

Schiller, D. (2001). A globalização e as novas tecnologias. Lisboa: Presença.

Wünsch, S. (2013, julho 13). Espionagem da NSA mostra como metadados podem expor segredos. Deutsche Welle. Recuperado de: <https://p.dw. com/p/1974t >. Acesso em: 30 jun. 2019. 